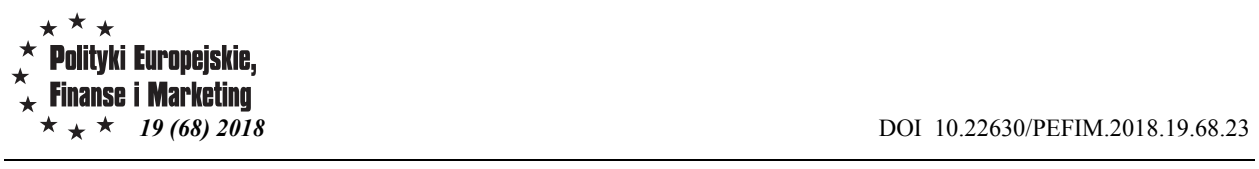

Natalia Wasilewska

Jan Kochanowski University in Kielce

Nadiia Davydenko

National University of Life and Environmental Sciences of Ukraine

\title{
FINANCIAL MANAGEMENT MODELING FOR ENTERPRISES
}

The purpose of the study was to model the financial management processes of enterprises to ensure the qualitative and complete forecasting of enterprise development. The analysis of the strategic matrix of interconnections through the use of power, logarithmic and polynomial trends during the determination of the tightness of the connection between the financial resources' volumes and the coefficients of liquidity and financial sustainability at the enterprise was carried out.

It is established that effective organization of scenario activity as an element of strategic planning is one of the main factors that will allow improving the system of financial management at the enterprise.

Key words: financial modeling, financial resources, liquidity coefficients, financial sustainability, scenario modeling, power, logarithmic and polynomial trends

\section{Introduction}

The financial security of an enterprise is determined by the provision of financial stability, liquidity and solvency, the efficiency of the use of available financial resources, the organization of internal control of the main activities of the enterprise, the analysis of possible internal and external threats to economic security and prevention of damage to its financial security, quality management of the entity. The constant compliance with financial security is conditioned by the task available to each entity i. e. ensuring the stability of the operation and achievement of the main strategic objectives of the enterprise.

Financial security of enterprises is one of the most important problem, particularly under conditions of economic instability.

Thus, in the external auditors' report on financial statements of one of the largest agroholdings in Ukraine AVANGARDCO IPL described the economic situation as extremely negative. Political and social unrest combined with the military conflict in the Donetsk and Lugansk regions has deepened the ongoing economic crisis, caused a fall in the country's gross domestic product and foreign trade, deterioration in state finances, depletion of the National Bank of Ukraine's foreign currency reserves, significant devaluation of the national currency and a further downgrading of the Ukrainian sovereign debt credit ratings. Following the devaluation of the national currency, the National Bank of Ukraine introduced certain administrative restrictions on currency conversion transactions, which among others included restrictions on purchases of foreign currency by individuals and companies, the requirement to convert $75 \%$ of 
foreign currency proceeds to local currency, a ban on payment of dividends abroad, a ban on early repayment of foreign loans and restrictions on cash withdrawals from banks. These events had a negative effect on Ukrainian companies and banks, significantly limiting their ability to obtain financing on domestic and international markets. The final resolution and the effects of the political and economic crisis are difficult to predict but may have further severe effects on the Ukrainian economy ${ }^{1}$.

There are some macroeconomic indicators in Ukraine over the past 10 years.

The Gross Domestic Product (GDP) in Ukraine expanded 0.20 percent in the third quarter of 2017 over the previous quarter. GDP Growth Rate in Ukraine averaged -0.09 percent from 2010 until 2017, reaching an all time high of 3.90 percent in the second quarter of 2010 and a record low of -4.70 percent in the third quarter of $2014^{2}$.

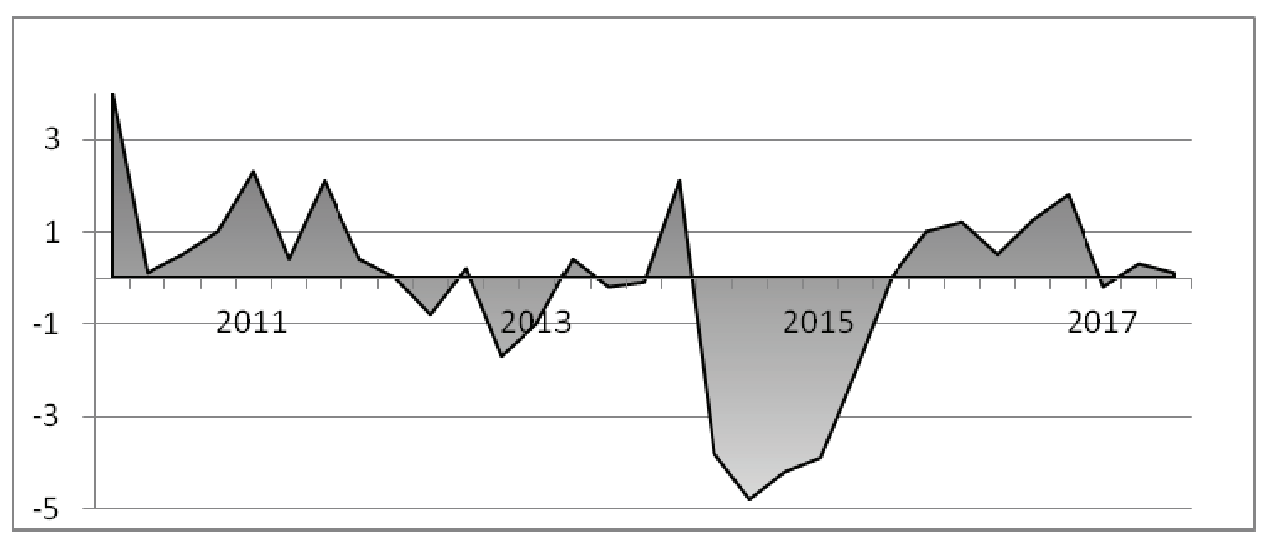

Figure 1. Ukrainian GDP Rate from 2010 until 2017, \%

Source: compiled by authors based on statistical information

Ukraine's consumer price inflation edged up to 13.7 percent year-on-year in December 2017 from 13.6 percent in the previous month and in line with market expectations.

\footnotetext{
1 Report and Consolidated Financial Statements for the year ended 31 December 2016. http://avangardco.ua/fileadmin/files/INVESTOR_RELATIONS/Annual_Reports/AVANGARDCO_IPL_Cons olidated_Fnancial_Statements_for_YE2016.pdf

${ }^{2}$ Trading Economics. https://tradingeconomics.com/ukraine/inflation-cpi.
} 


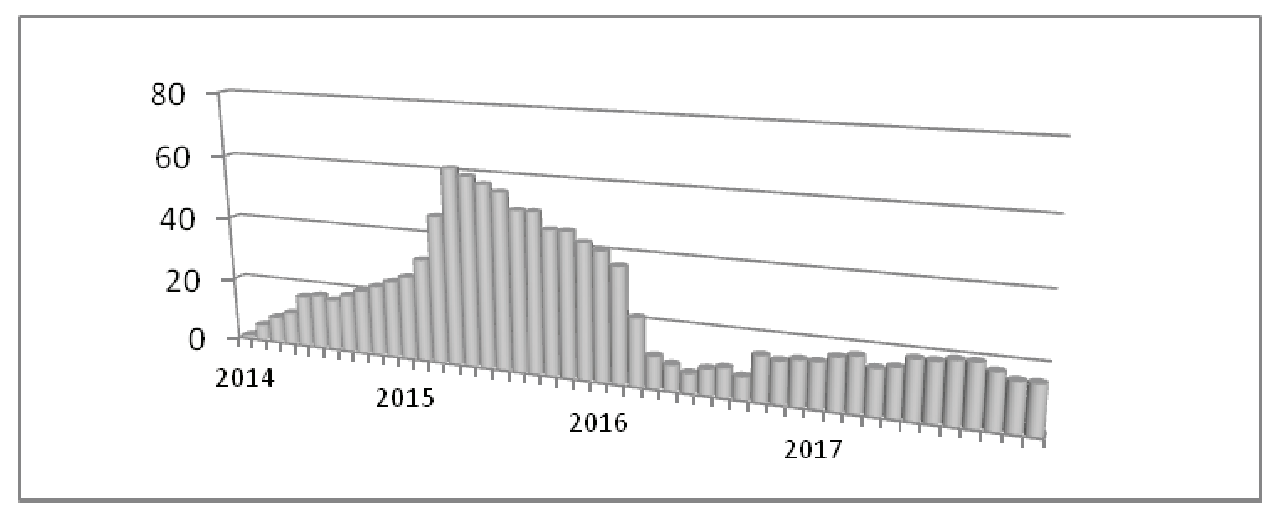

Figure 2. Inflation Rate from 2014 until 2017, \%

Source: compiled by authors based on statistical information

Upward pressure came mainly from food (17.7 percent), transport services (16.7 percent) and utilities (10.6 percent). On a monthly basis, consumer prices jumped 1 percent. Last year, the country's central bank raised its key interest rate twice in October and December in order to curb rising inflation. Inflation Rate in Ukraine averaged 34.84 percent from 1995 until 2017, reaching an all time high of 530.30 percent in September of 1995 and a record low of -1.20 percent in June of $2012^{3}$.

Ukraine recorded a trade deficit of 638.70 USD Million in November of 2017. Balance of Trade in Ukraine averaged -508.97 USD Million from 2001 until 2017, reaching an all time high of 688 USD Million in April of 2004 and a record low of 2364.90 USD Million in April of $2008^{4}$.

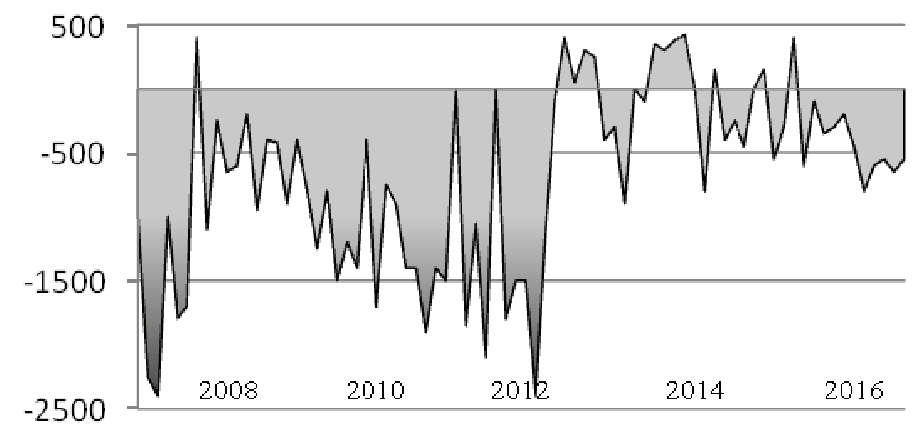

Figure 3. Ukraine Balance of Trade from 2008 until 2014, \%

Source: compiled by authors based on statistical information

\footnotetext{
${ }^{3}$ Statistical information. https://tradingeconomics.com/ukraine/inflation-cpi.

${ }^{4}$ Trading Economics. https://tradingeconomics.com/ukraine/inflation-cpi.
} 
As it can be seen from the figures, Ukrainian economy is really in such bad shape.

The above-mentioned preconditioned the purpose of the study, which consists in the scenario modeling of the processes of enterprises financial management to ensure the qualitative and complete prognosis of the enterprise development.

\section{Review of financial modeling techniques}

Mathematical modeling of the enterprise financial activity. Modern progressive, scientifically substantiated methods of financial management of enterprises include taking into account economic laws of management, justification of the system for the formation and use of monetary funds, systematic organization of financial management, the use of economical and mathematical methods and computer technologies ${ }^{5}, 6$.

The toolkit for optimizing financial management is complex and multifaceted. During the scientific research conducted by Bakaiev L.A. concerning the use of mathematical methods and economic systems models, the following algorithm for modeling of financial activity at the enterprise was proposed ${ }^{5,6}$. Mathematical modeling of the processes of an enterprise financial activity can be presented as a set of tasks, the decision of which should be carried out in several stages. It is supposed that the solution is realized on six levels of the detailed integrated management system (IMS) for business processes. At the upper level, the goal of the development (main goals) being implemented (IMS) is formalized. The next step is to execute management functions and tasks that can be detailed for each decision maker. In general, the task of constructing a management structure in an integrated management system can be represented by the following set of information ( $<\mathrm{A}, \mathrm{B}, \mathrm{C}, \mathrm{D}, \mathrm{F}, \mathrm{G}, \mathrm{K}, \mathrm{W}>$ ), where

$\mathrm{R}$ - tree of production goals and achievement of planned profit;

$\hat{\mathrm{A}}$ - a set of tasks implemented by an integrated management system;

$\hat{N}$ - a set of management functions implemented by an integrated management system;

$\mathrm{D}$ - a set of management objects;

$\mathrm{F}$ - a set of business processes;

$\mathrm{G}$ - a set of persons-decision makers who form an hierarchy of management;

$\mathrm{K}-\mathrm{a}$ set of criteria that provide performance evaluation;

$\mathrm{W}$ - a set of alternative options for a management structure implemented by the functions of an integrated management system.

It is established that at this stage essence of the problem and preconditions should be formed, same as assumptions should be accepted. It is necessary to highlight the most important signs and properties of the object being modeled, to study its structure and the relationship of its elements, at least in advance to formulate hypotheses that explain its potential behavior and development in time. This is the stage of formalizing the problem under study, that is, its expression in the form of specific mathematical dependencies. The construction of the model, in turn, is divided into several stages. First, the type of EMM is determined, the possibilities of its application in the given problem are studied;

\footnotetext{
${ }^{5}$ Bakaiev L. Mathematical Methods and Models of the Study of Economic Systems. Publisher Logos, Kiev, 2005 , p. 252

${ }^{6}$ Vovk V. Mathematical Methods of Operations Research in Economical and Production Systems. Publishing Center of Ivan Franko LNU, Lviv, 2007, p.101 - 224
} 
the specific list of variables and constraints, parameters and the form of interconnections are specified. If an object has a complex structure, several different models are being developed; there at each model allocates certain parts of the object, may be an input for another one, and so on.

If one uses a model that relates to a well-studied class, then the main thing is the substantiated assumption of the use of primary data. There is sometimes a situation in which a mathematical structure previously unknown is formed. At this stage, mathematical analysis of the model is carried out, revealing the general properties of the model through its possible solutions. Then it is important to prove the existence of a solution to the problem formulated. An analytical study finds out if the solution is the only one, what variables can be included in the decision, in what limits they can change, what are the possible trends of these changes ${ }^{7}$.

The third stage of simulation is the most complex one - it is the preparation of the information support of EMM. EMM imposes rigid conditions on the system of information provision, while one must keep in mind not only the development of information of the required quality, but also minimize the cost of forming information arrays.

The third stage is to transfer the knowledge from the model to the original, as a result, we form a plurality of knowledge about the initial object and move from the language of the model to the original language. And this is possible only when the result corresponds to the signs of currency (i.e., adequacy).

The fourth stage also includes the numerical solution of the economic-mathematical model. The greatest difficulty is to overcome the dimensionality of the nxm problem, which, as a rule, is multivariate, which is the basis for developing scenarios for the further development of financial activity of enterprises.

The fifth stage covers the analysis of the obtained numerical results and their application. This stage is aimed at studying of the feasibility and completeness of the simulation results and their application both in practical activity and in order to improve the model itself, as an adequate system of interconnections, the realization of which ensures the goal of development (Fig. 4).

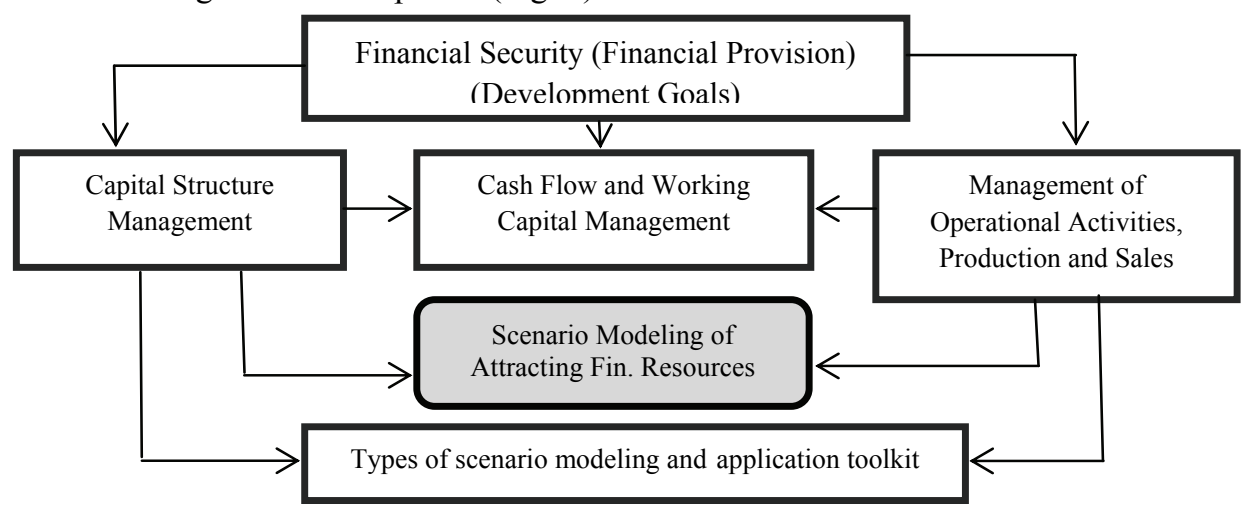

Figure 4. Interconnection of elements of scenario modeling of economic activity of enterprises Source: compiled by the authors

\footnotetext{
${ }^{7}$ Zahorodniy V., Kadievskyi V. Economic Modeling: Course of Lectures. Publisher VYD - p.h. DASOA, Kiyv, 2007, 214 p.
} 


\section{Methodology of an enterprise financial strategy formation}

The methodology of forming a financial strategy of an enterprise includes justification and development of such principles of activity, the introduction of which would allow interested entities to effectively solve identified problems ${ }^{8}$.

The basic principles of modeling the financial strategy of enterprises are to provide the accepted strategy of their sustainable development and basis on the theoretical model of the financial strategy, monitoring the organizational structure of an object and changes in it, the choice of alternative financial strategy from several predictable scenarios ${ }^{9}$.

The financial strategy of enterprises determines ways of attracting, accumulating as well as directions of spending financial resources. An organizational preparation of the procedure for forming the strategy up to interviewing senior staff of an enterprise, etc. is required ${ }^{8}$.

An important part of modeling a financial strategy is the definition and implementation of the sequence of this process.

The stages of modeling the financial strategy of an enterprise are as follows:

1. Description of the enterprise as an open dynamic system is carried out taking into account the influence on it of the factors of external and internal environment. Due to the results of the enterprise condition analysis it is necessary to obtain a picture of the means and possibilities to evaluate its positive and negative sides, to establish the possibilities of the existing financial structure and directions of its development. At the same time, it is important to: identify the boundaries of the enterprise in different spheres of a market economy; analyze socio-economic (including financial) potential of the enterprise; analyze the product market in the area of management; to define the position of the enterprise in the market ${ }^{8}$.

2. Definition of strategic goals. It is important to take into account different types of strategic goals, briefly, they can be represented as preserving existing positions of the enterprise on markets, increasing the volume of sales of products, while changing the proportions between them and changing the geography of markets, increasing volumes of product sales through the development of new product types, while preserving the geography of markets, reducing volume of product sales ${ }^{9}$.

3. Development of various types of the financial strategy due to the goals of the enterprise and taking into account the analysis of its potential ${ }^{9}$.

4. Formation of criteria for choosing options to create regulators out of reducing the number of alternatives developed; most often there are at least two selection criteria: the provision of the purpose of modeling and the availability of the lowest transaction costs to implement the choice of option ${ }^{10}$.

\footnotetext{
${ }^{8}$ Semenov A. Financial strategy in the management of the enterprise. Monograph. Publisher Classic Private University, Zaporizhia, 2008, p 156

${ }^{9}$ Davydenko N. Assessment and forecasting of attraction of financial resources by agrarian formations through IPO on the basis of scenario modeling. European Applied Sciences. Stuttgart, Germany, 62/2013.p. 142 - 147.

${ }^{10}$ Zahorodniy V., Kadievskyi V. Economic Modeling: Course of Lectures. Publisher VYD p.h. DASOA, Kiyv, 2007, p. 214
} 
5. Choosing the best option of the model scenario. It is important to give a methodologically grounded basis to create a base for choosing a strategy option. Strategies should be evaluated due to the following criteria: degree of achievement of the enterprise goal; economic efficiency (result); reliability of implementation; social and environmental acceptability; technological feasibility ${ }^{11}$.

6. Detailing of the selected option of the financial strategy model is carried out by bringing the general model to the level of filling it by the entities-executors, development of specific programs and projects. At this stage, it is important to prioritize tasks within the overall strategic development goals ${ }^{11}$.

7. Substantiation of the financial strategy of enterprises as a software product. At the final stage of the financial strategy formation, it takes the form of a mandatory implementation of the organizational and administrative document ${ }^{11}$.

Their achievements are made on the basis of the economic and mathematical model, which is a reflection of the scenario approach to substantiating the choice of the goal function $^{12}$, proposed by Zahorodniy V. Kadiievskyi V. and Davydenko N., which has the form (baseline scenario and derivatives from it) (Fig.5):

\section{Goal functions:}

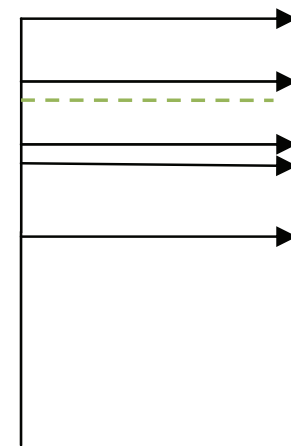

factors (efforts)

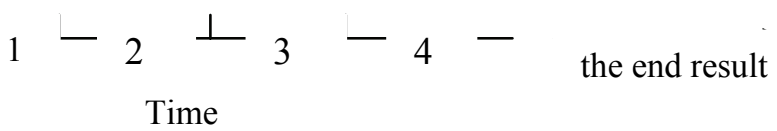

(time space)

Figure 5. Interconnections of initial conditions with the final result

Source: based on the economic and mathematical model proposed by by Zahorodniy V. Kadiievskyi V. ${ }^{12}$

The first scenario (baseline scenario). The internal-economic aspect; indicator: revenue:

$$
F_{1}(x)=\sum_{j=1}^{n} c_{j} x_{j} \rightarrow \text { max, }
$$

The second scenario. Enterprise assessment from the point of consumer view - consumer satisfaction with a certain type of goods or services:

\footnotetext{
${ }^{11}$ Semenov A. Financial strategy in the management of the enterprise. Monograph. Publisher Classic Private University, Zaporizhia, 2008. - $156 \mathrm{p}$

12 Zahorodniy V., Kadievskyi V. Economic Modeling: Course of Lectures. Publisher VYD - p.h. DASOA, Kiyv, 2007. $-214 \mathrm{p}$.
} 


$$
F_{2}(x)=\sum_{j=1}^{n} b_{j} x_{j} \rightarrow \max
$$

The third scenario. Financial aspect: the volume of attraction of financial resources taking into account the revenue:

$$
F_{3}(x)=\sum_{j=1}^{n}\left(\mathrm{c}_{\mathrm{j}} \mathrm{x}_{\mathrm{j}}-\mathrm{p}_{\mathrm{j}} x_{j}\right) \rightarrow \max ,
$$

The fourth scenario (the perspective development of the enterprise). Innovation aspect: profitability of innovations indicator:

$$
F_{4}(x)=\sum_{j=1}^{n} m_{j} x_{j} \rightarrow \max
$$

The developed economic and mathematical model has limitations:

Limitations on resource:

$$
\sum_{j=1}^{n} a_{i j} x_{j} \leq A_{i}
$$

Limitations on the main technical and economic indicators:

$$
\sum_{j=1}^{n} y_{r j} x_{j} \geq Y_{r}
$$

Limitations on financial resources and volumes of attracted resources:

$$
\sum_{j=1}^{n} k_{t j} x_{j} \leq K_{t}
$$

Limitations on demand:

$$
d_{j} \leq x_{j} \leq D_{j}
$$

Limitations on innovation costs:

$$
\sum_{j=1}^{n} v_{l j} x_{j} \leq V_{l},
$$

Limitations on the costs of compliance with product quality:

$$
\sum_{j=1}^{n} S_{h j} x_{j} \leq S_{h}
$$

where $x_{j}$ - the optimum desired volume of output of the j-th type, pcs.; $c_{j}$ - income from production of the unit of production of the $\mathrm{j}$-th type, $\mathrm{UAH}$;

$b_{j}$ - satisfaction of the consumer by the $\mathrm{j}$-th type of goods or services;

$p_{j}$ - expenses for production of the unit of production of the $\mathrm{j}$-th type, UAH;

$m_{j^{-}}$share of income per unit of products received as a result of the introduction of innovations in the production of $\mathrm{j}$-th type of products, $\mathrm{UAH}$;

$a_{i j}$ - the norm of the cost of the resource of i-th type per unit of j-th type UAH;

$A_{i}$ - the maximum allowable limit on the cost of a certain type of resource for the production of the entire product range, $\mathrm{UAH}$; 
$y_{r}$ - the value of $\mathrm{r}$-th indicator;

$Y_{r}$ - the minimum value of a certain technical and economic indicator;

$k_{j}$-amount of working capital (amount of variable costs), necessary for the production of a unit of a particular product type, UAH;

$K_{t^{-}}$the maximum amount of working capital available at the disposal of the enterprise, $\mathrm{UAH}$;

$d_{j} D_{j}$ - lower and upper limits of production, pcs.;

$v_{l^{-}}$Innovative costs per unit of production for a certain technology or for goods in general, UAH;

$V_{l^{-}}$the maximum amount of funds allocated for the innovation costs of the 1-th type, pes.;

$s_{h^{-}}$expenses for compliance with the quality of $\mathrm{j}$-th type of products for the $\mathrm{h}$-th technological operation, UAH;

$S_{h}$ - maximum amount of expenses for compliance with quality, UAH.

The economic and mathematical model is characterized by variants (alternatives) of economic measures, the realization of which is supposed in the limitations and concepts of scenario mathematical modeling.

At the same time, variants of the measures development determine the minimum costs of production means to achieve a certain goal; at these costs of funds or financial resources the goal is realized in an optimal way.

Such an approach leads to a rational combination of goal and means (need and opportunity) based on the methodology of scenario modeling.

\section{Scenario modeling of enterprises' financial management processes}

On the basis of the economic and mathematical model proposed by Zahorodniy V. and Kadiievskyi $\mathrm{V}$., scenario modeling of enterprises' financial management processes is proposed below ${ }^{13}$.

It is established that the basic principles of rational actions or behavior based on scenario modeling are principles of minimization or maximization of development, assessment of the state of the entities' and processes' functioning. In particular, the scenario modeling is carried out here not within the same model and transformation of the main indicators $\mathrm{a}_{\mathrm{ij}} \mathrm{b}_{\mathrm{i}} \mathrm{c}_{\mathrm{j}}$, but by transforming the model of type of limitation on sources of funds for capital investments itself:

$$
\sum_{t \in T} a_{t} z_{t}+\hat{x}-\overline{\bar{x}}=0
$$

- the profit that can be obtained in each year of the planning period;

$$
\frac{T-t}{t} Z_{0}+\frac{t}{T} Z_{t}-Z_{t}=0
$$

- the total amount of profit that can be obtained in the planned period:

$$
\sum_{j \in I} C_{j}^{T} x_{j}-x^{s t}-Z_{t}=0
$$

limitations on obtaining long-term loan loans, attracted resources:

13 Davydenko N. Assessment and forecasting of attraction of financial resources by agrarian formations through IPO on the basis of scenario modeling. European Applied Sciences. Stuttgart, Germany. Volume 62, 2013.p. 142 - 147. 
- volume of gross product, which provides the obtained optimal plan:

$$
\sum_{j \in I} C_{j}^{B} x_{j}-x^{B}=0
$$

- the volume of commodity products, which provides the obtained optimal plan:

$$
\sum_{j \in I} C_{j}^{T} x_{j}-x^{T}=0
$$

It is worth noting that the second feature of scenario modeling is that the economic and mathematical model has limitations that contain requirements, the conditions of which vary depending on the economic consequences of production activities and the impact of environmental factors on the entity's state (statistical or dynamic) ${ }^{13}$.

\section{Research results}

For the analysis of the strategic matrix of interconnections, the correlation dependencies for the investigated segments (enterprises) were calculated: the amount of financial resources $\mathrm{Y}$, received for each of them on the basis of account of:

$\mathrm{O}_{1}-$ liquidity coefficient;

${ }_{\mathrm{O}_{2}}$ - coefficient of enterprise financial stability.

In doing so, linear and polynomial trends were used to determine the tightness of the link between the volumes of financial resources and the coefficients of liquidity and financial stability (xj), as well as correlation dependencies were constructed.

For example, AVANGARDCO IPL was chosen. Briefly describe this enterprise. Avangard is a vertically integrated holding, one of the largest agroholdings in Ukraine. For this agroholding on the basis of the financial information two equations of dependence have been developed. Thus, the linear correlation dependence for $\mathrm{x}_{1}$ has the form: $\mathrm{y}_{1}=85782 \mathrm{x}_{1}-148471$, the correlation coefficient $\mathrm{R}^{2}=0.768$, and the determination coefficient is 0.8764 . For $\mathrm{x}_{2}$ the equation has the form $\mathrm{y}_{2}=136612 \mathrm{o}_{2}-$ 166531 , the correlation coefficient $R^{2}=0.880$. The results of the calculation of the pair correlation coefficients indicate that there is a direct relationship between the volume of financial resources and the coefficients of liquidity and the coefficients of financial stability, and this dependence is quite high. Thus, the change in the performance attribute $\mathrm{y}_{1}$ (volume of financial resources) by $76,8 \%$ depends on the factor attribute $\mathrm{x}_{1}$ (liquidity coefficient) and by $88.0 \%$ is explained by the change in the factor attribute $\mathrm{x}_{2}$ (financial stability coefficient).

The equation of multiple correlation has the form for the conditions of the linear trend: $y=157558+113761 \mathrm{x}_{2}+21090 \mathrm{x}_{1}, \mathrm{R}^{2}=0.8867$. The results of the calculations of the multiple correlation coefficient further confirm the influence of factor attribute on the resultant - so the change in the volume of financial resources by $88.67 \%$ is explained by factor attributes such as the coefficients of liquidity and financial stability.

The results of scenario modeling of the forecast of the development of the investigated enterprise are specified below are, taking into account three possible scenarios: optimistic, moderate and pessimistic based on historical data for 8 years. 


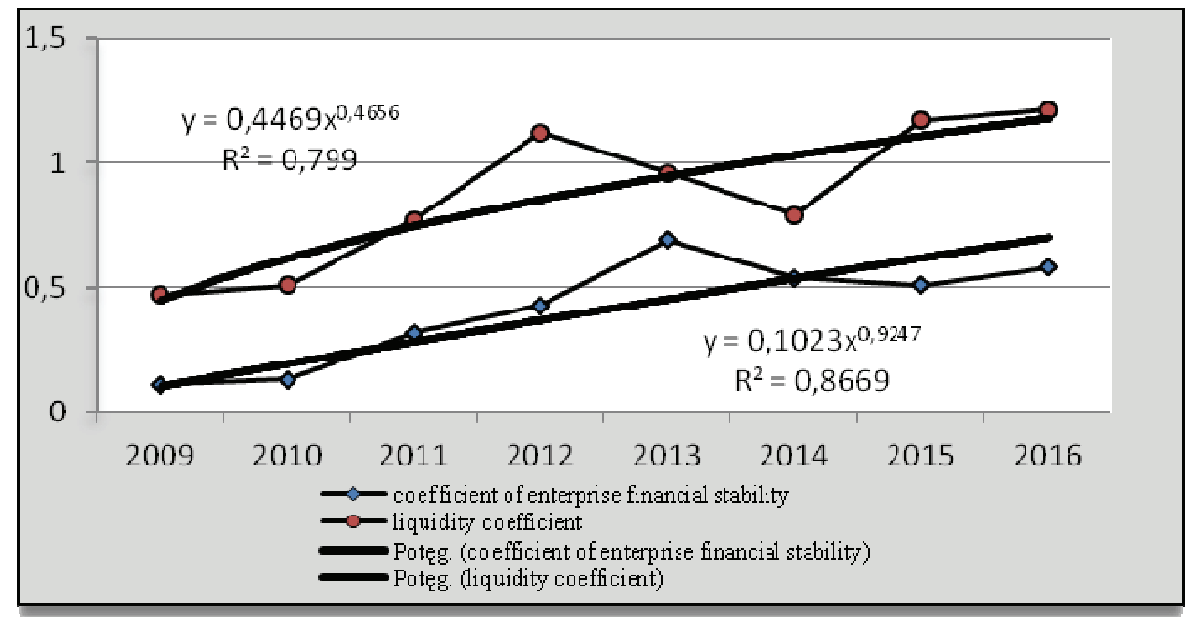

Figure 6. Optimistic development forecast based on scenario modeling for AVANGARDCO IPL Source: own research

For the conditions of the power trend with the optimistic forecast of development of AVANGARDCO IPL, the set of the equation of dependence has the form: $y=$ $0.1023 \mathrm{x}^{0,9247}$, the correlation coefficient is $\mathrm{R}^{2}=0.8669$ (financial stability) and $\mathrm{y}=$ $0.4469 \mathrm{x}^{0,4656}$, the correlation coefficient is $\mathrm{R}^{2}=0,799$ (the liquidity index).

Under these conditions, the results of the analysis models solution and forecast of enterprise performance indicators, enterprise management under uncertainty and risk conditions, production potential management models become limited by the right-hand side of the equations of the coordinating model (optimization of the production program) (Fig. 7).

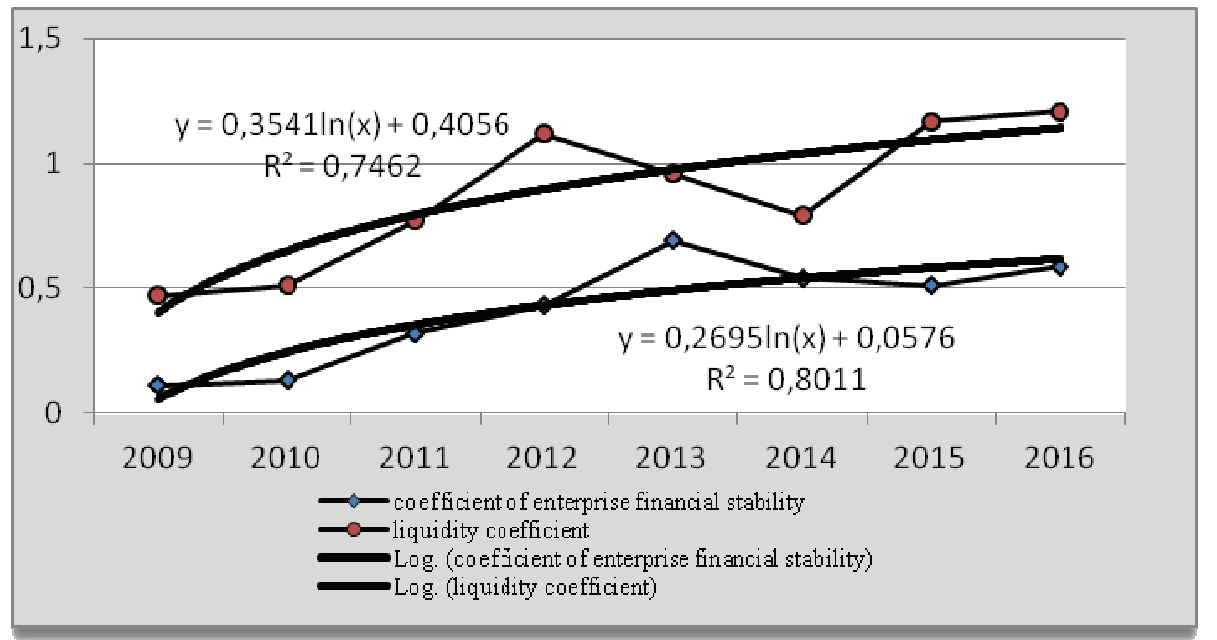

Figure 7. Moderate development forecast based on scenario modeling for AVANGARDCO IPL Source: own research 
With the moderate scenario of the enterprise development, the correlation equation changed as follows: $y=0,2695 \operatorname{In}(x)+0,0576$, the correlation coefficient is $R^{2}=0,8011$ (the coefficients of financial stability) and $\mathrm{y}=0,3541 \operatorname{In}(\mathrm{x})+0,4056$, the correlation coefficient is $\mathrm{R}^{2}=0,7462$ (the liquidity ratios).

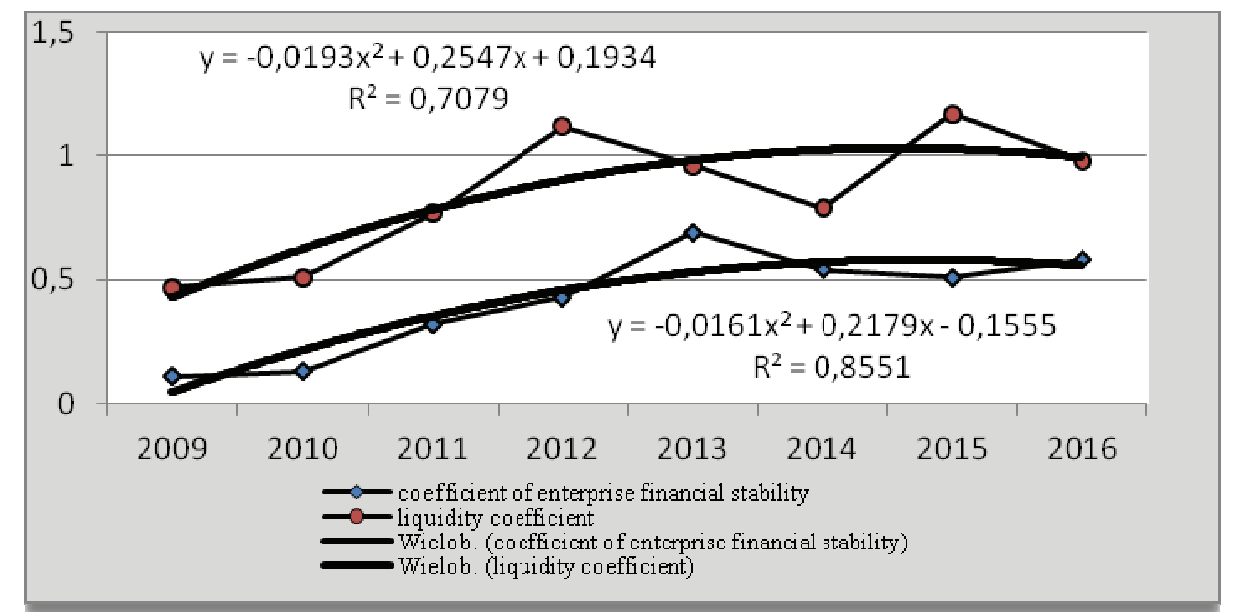

Figure 8. Pessimistic development forecast based on scenario modeling for AVANGARDCO IPL Source: own research

With the pessimistic forecast of development based on scenario modeling for AVANGARDCO IPL, the dependence equation has the form (depending on the change in liquidity and financial stability coefficients): $y=-0,0193$ o $^{2}+0,254700+0,1934$, the correlation coefficient is $\mathrm{R}^{2}=0,7079$ and $\mathrm{y}=-0,0161 \mathrm{o}^{2}+0,217900+0,1555$, the correlation coefficient is $\mathrm{R}^{2}=0,8551$.

\section{Conclusions}

1. The results of the forecasting of economic processes lay the foundation for the correct formulation of a particular task in specific financial situations. Unfortunately, most of the traditional methods of forecasting do not correctly consider the theory, patterns and variability of the external conditions of the operation of the forecast object.

2. The purpose of planning and forecasting as a management function is to timely take into account and evaluate all internal and external factors that provide favorable conditions for the normal functioning and development of enterprises. This activity is based on the identification and forecasting of consumer demand, the analysis and evaluation of available financial resources and the prospects for the development of economic conditions. One of the key factors in the successful operation of enterprises is the implementation of effective scenario planning, which would provide a qualitative and most complete modeling of the development options of the enterprise.

3. Analysis of the economic situation in Ukraine, the changes in key macroeconomic indicators that have taken place between 2007 and 2017 confirm that Ukrainian enterprises have functioned under difficult circumstances - devaluation of the national 
currency from 4,45 UAH/USD until 27,3 UAH/USD (more than 615\% over the past 10 years), GDP growth rate in Ukraine averaged -0,09 percent from 2010 until 2017, credit rating for Ukraine stands at B- or Caa2 (Fitch and Moody's appropriately).

4. Ukrainian enterprises EBIT (over the past five years) is of - 619538 million UAH. Only the objective assessment of the environment, analysis of enterprise strengths and weaknesses, effective activity forecasting, as well as financial modeling help enterprises adapt to the negative circumstances and achieve positive financial results. In this situation enterprises have to pay more attention to enterprise development modeling depending on the changes in the economic environment.

5. Obtained results of the forecast modeling of the investigated enterprise development, taking into account an optimistic scenario, a pessimistic scenario and a moderate scenario based on such coefficients as liquidity and financial stability, have proven that with the transformation from optimistic to pessimistic scenario the correlation between the resultant and the factor variables is weakened. Thus, for the optimistic scenario, the correlation coefficients are: $\mathrm{R}_{1}^{2}=0.799$ (based on liquidity ratios) and $\mathrm{R}_{\mathrm{s}}^{2}=0.867$ (based on financial stability coefficients), but for the pessimistic scenario, the values of these indicators are changed $-\mathrm{R}_{1}^{2}=0.7079$ and $\mathrm{R}_{\mathrm{s}}^{2}=0.855$. The research shows, AVANGARDCO IPL can expect for a positive financial dynamics into the future, but this situation is not so stable and strong, especially it is related to financial stability of the enterprise. Therefore, the company should pay much more attention to the risk diversification.

6. A focused strategy is a prerequisite for ensuring strong market positions of the enterprise and achieving its high financial performance in the long perspective. It is especially important in case of the enterprises have to function in the negative economical circumstances. Therefore, effective organization of scenario activities as an element of strategic planning, is considered as one of the main factors that will improve the system of financial management in the enterprise.

\section{Literature}

Bakaiev L. Mathematical Methods and Models of the Study of Economic Systems. Monograph. Publisher Logos, Kiev, 2005.

Davydenko N. Assessment and forecasting of attraction of financial resources by agrarian formations through IPO on the basis of scenario modeling. European Applied Sciences. Stuttgart, Germany. Volume 62, 2013.

Davydenko N. Strategy of providing financial stability of enterprises in the context of modern challenges and threats. Publisher Scientific herald of Uzhgorod University. The series "Economics". Edition 1(47). - V.1., 2016.

Rees M. Financial Modeling in Practice. Publisher: John Wiley \& Sons, 2008.

Report and Consolidated Financial Statements for the year ended 31 December 2016. http://avangardco.ua/fileadmin/files/INVESTOR_RELATIONS/Annual_Reports/AVANGARDC

O_IPL_Consolidated_Fnancial_Statements_for_Y̌E2016.pdf .

Samonas M. Forecasting, analysis and modeling: a framework for long-term forecasting. Publisher John Wiley \& Sons, 2015.

Semenov A. Financial strategy in the management of the enterprise. Monograph. Publisher Classic Private University, Zaporizhia, 2008.

Trading Economics. https://tradingeconomics.com/ukraine/inflation-cpi. 
Wasilewska N. Estimation of the Financial State of Agrarian Enterprises in Ukraine. Zeszyty Naukowe Szkoły Głównej Gospodarstwa Wiejskiego w Warszawie, Ekonomika i Organizacja Gospodarki Żywnościowej, 2010, V. 81.

Vovk V. Mathematical Methods of Operations Research in Economical and Production Systems. Publishing Center of Ivan Franko LNU, Lviv, 2007.

Zahorodniy V., Kadievskyi V. Economic Modeling: Course of Lectures. Publisher VYD - p.h. DASOA, Kiyv, 2007.

Informacja o autorze:

Prof. dr hab. Natalia Wasilewska

Jan Kochanowski University in Kielce

ul. Gieysztora, 2/63

02-999, Warszawa

E mail: n.wasilewska@unipt.pl 